\title{
Self-interest is overestimated: Two successful pre-registered replications and extensions of Miller and Ratner (1998)
}

\author{
*Cameron Brick \\ Department of Psychology, University of Amsterdam, 1012 WX \\ Amsterdam, Netherlands \\ brickc@gmail.com \\ https://orcid.org/0000-0002-7174-8193 \\ *Adrien Fillon \\ Department of Social Psychology, \\ Aix-Marseille University, Aix-en-Provence, \\ France \\ adrienfillon@hotmail.fr \\ *Siu Kit Yeung \\ Department of Psychology, University of Hong Kong, \\ Hong Kong SAR \\ yskjdm@yahoo.com \\ *Meiying Wang, *Hongye Lyu, *Jing Yee Jane Ho, *Sze Chai Wong \\ Department of Psychology, University of Hong Kong, \\ Hong Kong SAR \\ (wangmeiying98@gmail.com; elainelyu.lhy@ gmail.com; \\ jingyee.ho@gmail.com; nicolewong2210123@gmail.com) \\ ${ }^{\wedge}$ Gilad Feldman \\ Department of Psychology, University of Hong Kong, \\ Hong Kong SAR \\ gfeldman@hku.hk/giladfel@gmail.com

\section{In press at Collabra: Psychology} \\ Accepted for publication on April 11, 2021 \\ Word count: abstract - 226, manuscript excluding references - 7445
}

*equal-contribution first author

^corresponding author Gilad Feldman, gfeldman@hku.hk 
Data availability: All data and code are publicly available at https://osf.io/57mdc/

Competing interests: The authors declared no potential competing interests with respect to the authorship and/or publication of this article.

Financial disclosure/funding: The research was supported by the Teaching Development Grant of the University of Hong Kong.

Additional information: This paper was part of a larger project, 'Mass pre-registered replications in judgment and decision-making' led by the senior author. The project aims to revisit well known research findings in the area of judgment and decision making and investigate their replicability. Collaborative Open-science REsearch (2020). Replications and extensions of classic findings in Social Psychology and Judgment and Decision Making. DOI 10.17605/OSF.IO/5Z4A8. Retrieved from http://osf.io/5z4a8 and http://mgto.org/pre-registered-replications/

Acknowledgments: We thank Henrik Y. L. Pröpper for conceptual input on the introduction.

Authorship declaration: Please see the table below. The pre-registration authors were primarily responsible for the empirical methods, results, and first drafts, and therefore were essential. All authors approved the final manuscript for submission.

\section{Contributor roles taxonomy}

\begin{tabular}{|c|c|c|c|c|c|c|c|c|}
\hline Role & HY & WC & $\mathrm{LH}$ & WM & GF & $\mathrm{AF}$ & WY & $\mathrm{CB}$ \\
\hline Conceptualization & & & & & • & & & \\
\hline Pre-registration & - & • & - & • & & & & \\
\hline \multicolumn{9}{|l|}{ Data curation } \\
\hline Formal analysis & • & • & - & - & & & & • \\
\hline Funding acquisition & & & & & • & & & \\
\hline Investigation & $\bullet$ & $\bullet$ & • & • & & & & \\
\hline $\begin{array}{l}\text { Pre-registration peer review / } \\
\text { verification }\end{array}$ & & & & & • & • & • & • \\
\hline $\begin{array}{l}\text { Data analysis peer review / } \\
\text { verification }\end{array}$ & & & & & • & • & • & • \\
\hline Methodology & • & $\bullet$ & • & • & & & & \\
\hline Project administration & & & & & $\bullet$ & & & • \\
\hline Resources & & & & & • & & & \\
\hline Software & • & $\bullet$ & & • & & • & & • \\
\hline Supervision & & & & & - & & & • \\
\hline Validation & $\bullet$ & $\bullet$ & & & & • & & • \\
\hline Visualization & • & • & & • & & - & & • \\
\hline Writing-original draft & • & • & • & • & & & & • \\
\hline Writing-review and editing & & & & & $\bullet$ & • & $\bullet$ & • \\
\hline
\end{tabular}

Note. See https://www.casrai.org/credit.html for the details and definitions of each role. 


\begin{abstract}
Self-interest is a central driver of attitudes and behaviors, but people also act against their immediate self-interest through prosocial behaviors, voting incongruously with their finances, or punishing others at personal cost. How much people believe that self-interest causes attitudes and behaviors is important, because this belief may shape regulation, shared narratives, and institutional structures. An influential paper claimed that people overestimate the power of selfinterest on others' attitudes and behavioral intentions (Miller \& Ratner, 1998). We present two registered, close, and successful replications (U.S. MTurk, $N=800$; U.K. Prolific, $N=799$ ) that compared actual to estimated intentions, with open data and code. Consistent with the original article, participants overestimated the impact of payment on blood donation in Study $1, d \mathrm{~s}=0.59$ $[0.51,0.66], 0.57[0.49,0.64]$, and overestimated the importance of smoking status for smoking policy preferences in Study 4, $d \mathrm{~s}=0.75[0.59,0.90], 0.84[0.73,0.96]$. These replications included two extensions: 1) communal orientation as a moderator of overestimation and 2) a more detailed measure of self-interest in Study 4 (ordinal smoking status). Communal orientation did not predict overestimation, and the ordinal smoking measure yielded similar results to the main study. Verifying the overestimation error informs behavioral theories across several fields and has practical implications for institutions that require trust and cooperation. All materials, data, and code are available at osf.io/57mdc/.
\end{abstract}

Keywords: self-interest; judgment; bias; decision making; attribution; pre-registered replication; 
Self-interest is overestimated: Two successful pre-registered replications and extensions of Miller and Ratner (1998)

How much do personal interests drive others' attitudes and behaviors? Self-interest is fundamental in behavioral theories across the sciences such as in rational choice theory, evolutionary psychology, behaviorism, criminology, and beyond (Agnew, 2014; Barkow, Cosmides, \& Tooby, 1995; Force, 2003; Miller, 1999; Nelson, 2020). People are also compelled by the idea that self-interest is the primary driver of the attitudes and behaviors of others. Individuals tend to attribute prosocial actions to intentions for personal gain (Gardner \& Ryan, 2020) and maintain such narratives of self-interest even in the face of disconfirming evidence (Critcher \& Dunning, 2011). These beliefs are deeply consequential: they inform not just personal interactions but also public policies and institutions such as the criminal justice system. As a more specific example, people might believe in 2021 that most people would choose not to wear face masks, choosing self-interest over community disease prevention, but compliance is high.

Similarly, evidence is growing that people also think and act against their immediate selfinterest by helping, sharing, funding, and cooperating (Batson \& Powell, 2003; Besley \& Ghatak, 2018). In addition, self-interest such as financial gain is a surprisingly weak predictor of voting and policy preferences (Caplan, 2011). Individuals are also concerned with ideology, equality, fairness, and collective outcomes when making decisions (Dawes, van de Kragt \& Orbell, 1988; Sears \& Funk, 1990; Tyler, 1990; Güth \& Kocher, 2014; Mahmoodi et al., 2015). The extent to which scientists and the public assume that self-interest drives attitudes and behaviors has implications for behavior change theories, public policy, charitable giving, conservation, 
criminology, and organizational management (Agnew, 2014; Felin \& Foss, 2009; Kals, Maes, \& Becker, 2001; Ostrom, 1990/2011; Ratner \& Miller, 2001; Ratner, Zhao, \& Clarke, 2011).

\section{Choice of Replication Target}

By comparing estimates to actual choices, one landmark paper challenged the central concept that people make rational decisions to maximize personal gain (Miller \& Ratner, 1998). They provided evidence that individuals overestimate how much self-interest determines the intentions and preferences of other people. For example, how much do financial incentives affect prosocial behavior, and how much does a person's smoking status determine their preferences for smoking bans? Seeing self-interest as primary continues to influence theory and practice, particularly in political science, management, social psychology, and economics. In March 2021, Miller and Ratner (1998) had been cited 487 times on Google Scholar. As far as we know, there have been no published close replications. Importantly, self-reported willingness was used as a proxy for behavior in the original and our replication, and therefore any discrepancy between estimates and reported willingness could also be explained by differences between reported willingness and actual behavior. However, the overestimation interpretation is most plausible based on evidence from different designs (Vuolevi \& Van Lange, 2009) and findings that people think of others as more selfish and less fair than themselves (Van Lange \& Sedikides, 1998).

Miller and Ratner (1998) informed the perennial tension between self-interest and the common good. Overestimating self-interest was consistent with large-scale studies on political attitudes finding that vested personal interests hardly predict individuals' attitudes towards policies, even on issues that should be highly relevant to considerations of self-interest (Boninger, Krosnick, \& Berent, 1995; Jost, Banaji, \& Nosek, 2004). The overestimation effect shows that early conceptions of self-interest were too narrow for overlooking motivations such 
as being a good group member. Another influential study that cited Miller and Ratner (1998) was 'Party over policy' (Cohen, 2003) on the influence of group memberships on political attitudes (1179 citations on Google Scholar). While Cohen's participants were unaware of how selfinterest drove their own beliefs, they readily assumed that self-interest drove the beliefs of their political adversaries. Miller and Ratner (1998) is also part of the foundation of arguments about self-interest in moral psychology and decision making, and has implications for altruism and prosocial behaviors. For example, follow-up studies continued to target self-interest in promoting charity donation rather than other frameworks (Simpson, Irwin, \& Lawrence, 2006).

Based on similar studies, Ratner and Miller (2001) proposed that the assumption of selfinterest could be self-fulfilling through a positive feedback loop between theory and social structures. Believing that humans are mostly self-interested led to the design of social institutions that facilitated this outcome. It is hard to overstate the potential importance of this feedback loop, and psychologists could partner with experts in institutions to better understand how assumptions of self-interest might have informed the design of educational systems, branches of government, economic models, and also smaller contexts such as workplace regulations. Additionally, strong social norms of self-interest may lead people to behave in self-interested ways just to avoid norm violations. "People treat self-interest as a natural law and because they believe they should not violate a natural law, they try to obey it" (Kagan, 1989) (p. 283). Similarly, institutional design, norms, stories, literature, and management practices can lead to self-fulfilling processes based on popular ideas (Ferraro, Pfeffer, \& Sutton, 2005). Therefore, beliefs about self-interest appear to impact practical as well as theoretical outcomes (Ghoshal \& Moran, 1996; Ratner \& Miller, 2001; Vuolevi \& Van Lange, 2009), and such beliefs may reduce trust and cooperation (Darke \& Chaiken, 2005; Evans \& Krueger, 2016). 
Debates continue about whether people overestimate how much self-interest drives others' preferences. Inaccurate estimations of other groups are also demonstrated in political psychology: members of political groups overestimate how different their political opponents' policy positions are (Van Boven, Ehret, \& Sherman, 2018). Another impactful study suggested that people actually underestimate the influence of self-interest (Epley \& Dunning, 2000). Their studies compared charitable behaviors predictions for self and others, compared to only attitudes in previous studies. Participants overestimated the likelihood that they would act in generous ways by incorrectly weighing moral sentiments over self-interest and overlooking base rates, but participants predicted others' behavior more accurately. These authors argued that when hedonic consequences are immediate, as in their study designs, self-interest influences behavior, and people's cynical beliefs about others are likely to be accurate. However, when hedonic concerns are remote, as in hypothetical choices like in Miller and Ratner (1998), self-interest is less influential and people are more likely to overestimate its impact. Separate from resolving these boundary effects and potential moderators, these are examples of how Miller and Ratner (1998) is woven into subsequent theory and therefore worth replicating. An important note is that these studies and the current ones were based on Western samples, which leaves a large gap about how most of the world's population would respond to such scenarios.

We did not know if the key effect would replicate even within a Western sample. An informal Twitter poll yielded the second-lowest estimation of successful replication among 12 effects (Feldman, 2020). We tested the classic overestimation effect on self-interest in two samples and two domains (blood donation and smoking-related policies). Our goal was to evaluate reproducibility and replicability in response to a growing recognition of their importance in psychological science (Open Science Collaboration, 2015; Zwaan, Etz, Lucas, \& 
Donnellan, 2017). We present two pre-registered, well-powered, independent, very close replications of Miller and Ratner (1998), with open data, code, and RMarkdown output. We chose Studies 1 and 4 (originally $N s=56$ and 81) because they were the most straightforward designs to replicate closely and feasibly online; for example, the original Study 2 was a poor candidate because it was about abortion and appeared deeply contextualized in a specific political era in the USA. There is no Study 2 nor Study 3 in this project; we conducted two studies and both are reported here using the study numbers from the original paper for ease of comparison.

\section{Original Study Design}

In Study 1, participants were randomized to report both a) their self-reported willingness to donate blood with and without a financial incentive and b) their estimate of others' willingness with or without a financial incentive. The mean reported willingness was then compared to the mean estimated willingness across payment conditions. In Study 4, separate participants were randomized to either report their smoking status (yes/no) and then indicate their support of eight policies that restricted smoking, or to estimate the willingness of other smokers and nonsmokers to endorse those policies. Similarly, the mean policy support for smokers vs. nonsmokers was compared to the estimated support of those groups.

Table 1

Hypotheses of Miller and Ratner (1998)

Study Hypothesis

1 1A: Participants overestimate how much payment changes others' willingness to donate blood. 1B: The individual tendency to overestimate is unrelated to how much payment influenced that individual's willingness to donate blood.

$4 \quad$ 4A: Smokers are more opposed than nonsmokers to policies restricting smoking. 
4B: Participants overestimate the impact of smoking status on others' attitudes towards these policies.

Note. Original effect sizes were not provided and could not be precisely estimated because variance was not reported either. Hypothesis $1 \mathrm{~B}$ predicted a null effect and the result was reported as " $F(1,54)<1, n s$."

The original paper confirmed all of these predictions. The ostensibly large effects (from visual inspection; no variance was reported) could either be signs of a robust phenomenon or signs of research practices that were normal at the time but are now recognized as inflating effect sizes and false positives (John, Loewenstein, \& Prelec, 2012). Given the era, the original article was normative in lacking open data, code, transparency about the timing of analytic decisions, information about a file drawer, or complete descriptives (e.g., SDs were missing). Further, the samples were small and the tests weakly powered (Table 2). At the same time, these findings might be expected to replicate given that over-estimation was shown in multiple contexts across quite distinct methods and topics in the original paper, and in related papers since.

\section{Replication Pre-registrations}

Both replications were pre-registered prior to data collection at the Open Science Framework (Nosek \& Lakens, 2014) including pre-planned analyses and simulated data (reported in the pre-registration Supplements). The replications were conducted in parallel by different teams working independently. Anonymized data, code, and files from the current manuscript are here: https://osf.io/57mdc/. This link also includes the pre-registrations, original manuscripts, code, Qualtrics exports, and pre-registration supplements of both independent samples. Minor deviations from these pre-registrations are listed in the Supplement.

All studies, samples, measures, manipulations, and exclusions conducted for this investigation are reported, all inferential tests not explicitly marked "exploratory" were pre- 
registered with power analyses, and data collection was completed before hypothesis testing. All $t$-tests were two-tailed and $\alpha=.05$.

\section{Power and Sensitivity Analyses}

The power analyses in the pre-registration supplements were based on estimations of the unreported original variance, and therefore were speculative. The sample size in each replication was ten times larger than the original. Sensitivity analyses run in the R package pwr using $\alpha=$ $.05, \beta=.80, N=799$ showed the minimum effect detectable for each hypothesis in each separate sample: H1A, H4B one-sample $t$-tests, $d=.10$; H1B, H2A:F, H4A Pearson's correlations, $r=$ .10. The combined sample analyses for $N=1598$ were more sensitive, yielding $d=.07$ and $r=$ .07 , respectively.

\section{Participants and Overview}

All participants completed Studies 1 and 4 in randomized order to minimize order effects (in the 1998 paper, participants only completed one of the studies). After every scenario, the participants responded to comprehension questions to make sure they understood the content. Also, the results are overall very similar between the two samples, which suggests there were not major quality issues. Finally, we used planned exclusions for lack of English proficiency or selfreported lack of understanding the materials. The replication sample characteristics are compared to the original article in Table 2.

Table 2

Samples from the Original Study and Replications

\begin{tabular}{llll}
\hline & Miller and Ratner (1998) & MTurk & Prolific \\
\hline$N$ & $N_{\mathrm{S} 1}=54, N_{\mathrm{S} 4}=81$ & 799 & 799
\end{tabular}




\begin{tabular}{lllc} 
Country & USA & USA & UK \\
Sample & Students & \multicolumn{2}{c}{ General population } \\
$\%$ Female & Unknown & $49.1 \%$ & $59.6 \%$ \\
Age, $M$ & Unknown & 41.6 & 40.8 \\
Age range & Unknown & $19-78$ & $18-76$ \\
Setting & On paper in person & \multicolumn{2}{c}{ Online by computer } \\
Compensation & Study 1: course credit or \$5 & \$0.90 for 6 £0.70 for 6 \\
& Study 4: unknown & minutes minutes \\
Year & 1998 & \multicolumn{2}{c}{2019} \\
\hline
\end{tabular}

\section{MTurk}

A total of 800 United States residents recruited through Amazon Mechanical Turk (MTurk) completed the study through Cloudresearch/TurkPrime (Litman, Robinson, \& Abberbock, 2017) (age $M=41.6$ years, $S D=12.8 ; 401$ men, 393 women, and six other/rather not disclose). One person reporting an age of 11 was excluded; this was not pre-registered, and see the Supplement for a complete list of deviations. For Study 4, the MTurk sample was randomized to either the direct replication $(n=414)$ or the extension with a more granular measure of smoking status $(n=386)$.

\section{Prolific}

A total of 799 United Kingdom residents recruited through Prolific completed the study (age $M=40.8$ years, $S D=13.7 ; 319$ men, 476 women, and four other/prefer not to say); for demographics of the overall Prolific population, see (Palan \& Schitter, 2018). For example, the modal Prolific panel member in the larger population was employed full-time and had a bachelor's degree.

\section{Sample quality}

Online panel samples offer improved external validity compared to student samples due to more representative population sampling (Mason \& Suri, 2011; Palan \& Schitter, 2018). For 
example, because we sought to generalize the findings to all adults, these samples include a wide range of ages (18-78). Additionally, classic psychological effects replicate in these online populations (Berinsky, Huber, \& Lenz, 2012; Hauser \& Schwarz, 2016).

\section{Replication Closeness and Evaluation Criteria}

We compared the replication effects using established criteria (LeBel, Vanpaemel, Cheung, \& Campbell, 2019) and classed both samples as very close replications (Table 3).

Table 3

Replication Closeness

\begin{tabular}{|c|c|c|}
\hline Design facet & Replication & Deviation from the original study \\
\hline Effect/hypothesis & Same & $n / a$ \\
\hline IV construct & Same & $n / a$ \\
\hline DV construct & Same & $n / a$ \\
\hline $\begin{array}{l}\text { IV operationalization } \\
\text { DV operationalization }\end{array}$ & $\begin{array}{l}\text { Same } \\
\text { Same }\end{array}$ & Minor wording differences (Tables S1 and S2) \\
\hline Population (e.g., age) & Similar & $\begin{array}{l}\text { The original studies used U.S. introductory students at the } \\
\text { State University of N.Y. in Study } 1 \text { and Princeton University in } \\
\text { Study 4. We sampled MTurk (U.S. residents) and Prolific } \\
\text { (U.K. residents), which are more diverse and older populations. }\end{array}$ \\
\hline IV stimuli & Similar & $\begin{array}{l}\text { The vignette in Study } 1 \text { was changed from the Mandela Room } \\
\text { of the student union to the neighborhood of the participant. }\end{array}$ \\
\hline DV stimuli & Same & $n / a$ \\
\hline Procedural details & Different & $\begin{array}{l}\text { Each participant completed two studies instead of only one. } \\
\text { Order effects were minimized through random assignment. }\end{array}$ \\
\hline Physical settings & Different & $\begin{array}{l}\text { The original studies used a questionnaire packet in person and } \\
\text { the replications used online participation using a computer. }\end{array}$ \\
\hline Contextual variables & Different & $\begin{array}{l}\text { The original studies were reported in } 1998 \text { or earlier and the } \\
\text { replications were conducted in } 2019 .\end{array}$ \\
\hline $\begin{array}{l}\text { Replication } \\
\text { classification }\end{array}$ & \multicolumn{2}{|c|}{ Very close replications } \\
\hline
\end{tabular}

\section{Study 1}


This study investigated the impact of financial incentives on the reported willingness to donate blood. Participants estimated the likelihood to donate blood for themselves and others, both when there was payment and when there was none.

\section{Method}

Participants completed a two-condition (payment or not) within-subjects design nearly identical to the original (see Table 3, and Table S1 for the vignette text). Participants were told that the blood supply in the United States had reached record lows in the past month and that the American Red Cross would be coming to the neighborhood for a blood drive in several weeks. The Red Cross was asking to get a sense of how many people would be willing to donate blood and what factors might make volunteering more attractive. Both the US and UK samples saw the same text about the American Red Cross.

\section{Manipulation: Payment}

In the paid condition, participants were told that the Red Cross was considering paying $\$ 15$ to each individual who donates blood. In the unpaid condition, participants were told that the Red Cross was considering collecting donations without financial compensation. Participants saw both payment conditions in random order.

\section{Extension: Communalism}

Thinking about social interactions in terms of self-interest could lead a person to act competitively and selfishly due to limited perceived resources (Kool, 2008). This focus may also lead individuals to suspect others are driven primarily by self-interest (Kool, 2008). In contrast, when individuals are more communally oriented, self-interest may be less important both in their decision making and for their perceptions of others' behaviors. 
This extension tested communalism as a potential moderator of overestimation.

Communal motivation means believing that others' needs and feelings are vital in relationships and that people should help and care for each other (Clark, Oullette, Powell, \& Milberg, 1987). Individuals with higher communal motivation care more for the welfare and needs of others, and expect others to be responsive and concerned about their welfare. A meta-analysis recently showed that communal motivation is positively associated with personal well-being and relationship partner satisfaction (Le, Impett, Lemay, Muise, \& Tskhay, 2018). Compared to less communal individuals, we hypothesized:

Hypothesis 2. More communal individuals will report being more willing to donate blood (H2A) and support restrictive smoking policies $(\mathrm{H} 2 \mathrm{~B})$; More communal individuals will more often estimate that others are willing to donate blood (H2C) and support restrictive smoking policies $(H 2 D)$;

and the key test:

More communal individuals will overestimate self-interest less in estimates for donation (H2E) and policy support $(\mathrm{H} 2 \mathrm{~F})$ (i.e., estimate more accurately).

The results of Hypothesis 2 are at the end of the Results section.

\section{Measures and Procedures}

Communalism was measured with the 14-item Communal Orientation Scale (Clark et al., 1987) (see Supplement for all items). An example item was "When making a decision, I take other people's needs and feelings into account", rated from 1 (extremely uncharacteristic of me) to 7 (extremely characteristic of me); Cronbach's $\alpha=.84$. Participants then indicated whether they would donate blood (yes or no) for both payment conditions. Participants then estimated the 
percentage of their peers who would donate blood by giving a number from 0 - $100(\%)$ for both payment conditions.

\section{Original Effect Sizes}

Miller and Ratner (1998) did not report effect sizes, and they could not be calculated precisely because standard deviations or other variance measures were not reported. However, the replication effects were compared with the original (LeBel et al., 2019). There are normally three components to the interpretation. Signal indicates a significant effect, Consistency is whether the effect size is comparable, e.g., whether 95\% CIs cover the original effect size, and Direction clarifies the direction of any inconsistencies. To be cautious, we do not precisely estimate the original effect sizes and therefore only provide Signal and Direction from this replication framework. The original effects look very large (see "difference" row in Table 4) and the direction was always consonant with the original.

Related studies can also inform a likely replication effect size. Few experiments report comparisons of actual to estimated self-interest with similar paradigms, but one such study used a dice-rolling method (Vuolevi \& Van Lange, 2009) and showed that participants overestimated how much self-interest drove behavior in a financially incentivized task. We converted the $t$-test results in (Vuolevi \& Van Lange, 2009) Study 2 to an overestimation effect of $d=0.96$, which appears visually comparable to Miller and Ratner (1998).

\section{Results}

The Study 1 descriptives are shown in Table 4 for the original (1998) and both replication samples across self-rating and estimates for others. Reported willingness to donate was computed by a mean of no (0) or yes (1), then multiplied by 100 to yield a percentage; estimated willingness was a simple mean within payment conditions within each study. 
Table 4

Blood Donation Rates in Study 1

\begin{tabular}{lcccccc} 
& \multicolumn{3}{c}{ Self } & \multicolumn{3}{c}{ Others (Estimated) } \\
\hline & Original & MTurk & Prolific & Original & MTurk & Prolific \\
\hline$n$ & 54 & 799 & 799 & 54 & 799 & 799 \\
\hline & & $\%$ & & & $M(S D)$ \\
Paid & 73.2 & 72.7 & 76.8 & $62.5(?)$ & $55.8(27.0)$ & $59.9(26.4)$ \\
Unpaid & 62.5 & 59.2 & 71.2 & $32.6(?)$ & $37.9(26.0)$ & $42.4(27.8)$ \\
\hline Difference & 10.7 & 13.5 & 5.7 & 29.9 & 17.9 & 17.5 \\
\hline
\end{tabular}

Note. SDs were not reported in the original paper.

Figure 1

Estimated Donation Willingness (\%) by Payment (Study 1; $\mathrm{N}=1598$ )

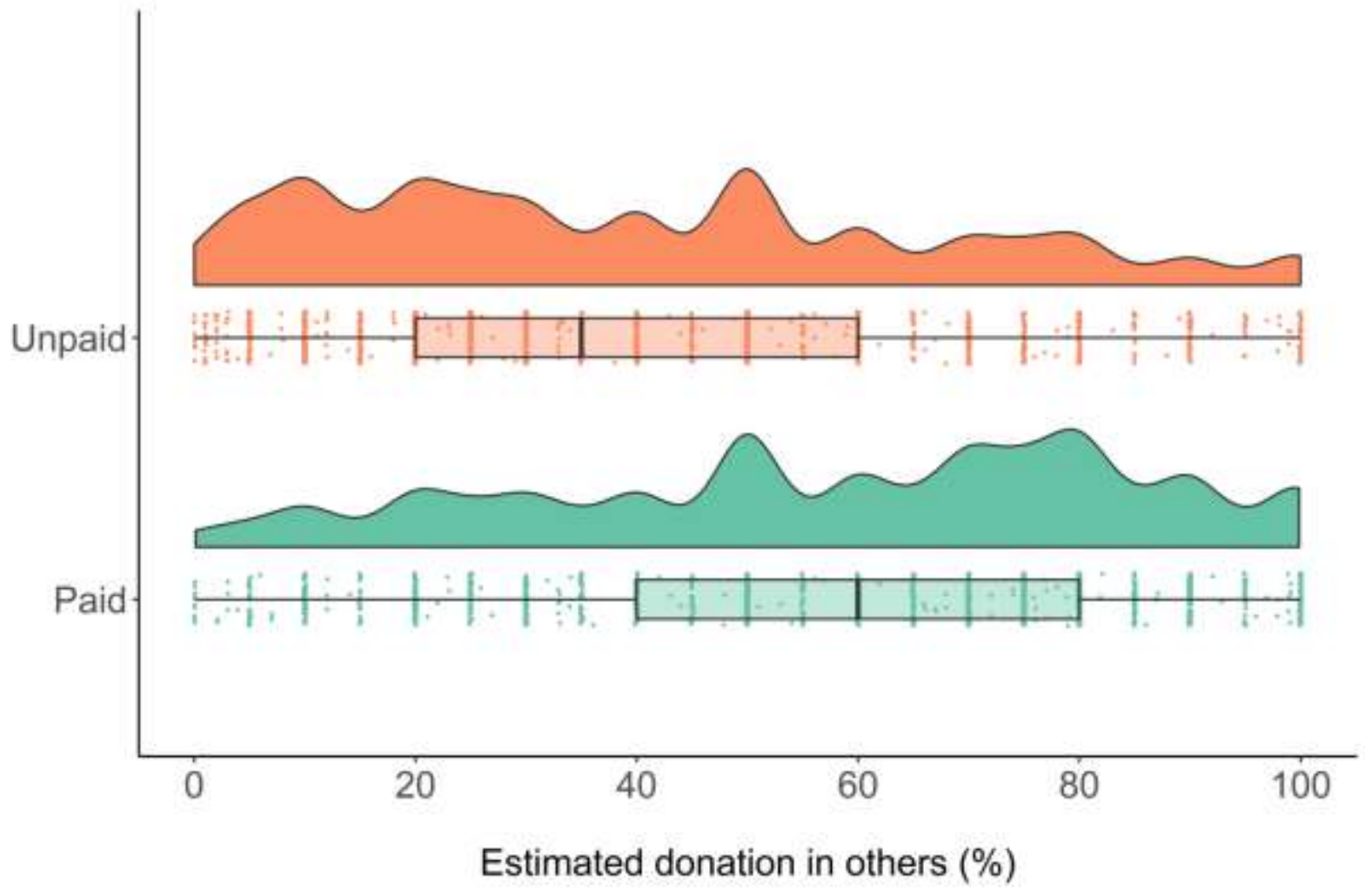


Note. Shown as raincloud plots (Allen, Poggiali, Whitaker, Marshall, \& Kievit, 2019). The boxes indicate the interquartile range of that row (25-75\%), the whiskers the values within 1.5 times that range, and the vertical black lines the medians.

\section{Replication}

The key overestimation effect is shown below in Hypothesis 1A. See Table S3 for the effect of payment on donation willingness and on estimates, and Figure 1 for the estimated donation willingness by payment. All effect sizes below are shown followed by $95 \%$ CIs.

Being paid increased the self-reported willingness to donate blood, based on pairedsample $t$-tests, $t(798)=4.17, p<.001, d=0.13[0.07,0.19]$ for the Prolific sample and $t(798)=$ $8.5, p<.001, d=0.29[0.22,0.35]$ for the MTurk sample. As expected, participants estimated that others would be more willing to donate blood when paid, $t(798)=23.7, p<.001, d=0.64$ $[0.58,0.7]$ for the Prolific sample and $t(798)=24.3, p<.001, d=0.67[0.61,0.73]$ for the MTurk sample.

Participants underestimated donation rates in both conditions based on one-sample t-tests: willingness to donate was higher than estimated in the paid condition: $t(798)=11.84, p<.001$, $d=0.48[0.38,0.58]$ for Prolific, $t(798)=10.88, p<.001, d=0.46[0.36,0.56]$ for MTurk; and the unpaid condition: $t(798)=18.29, p<.001, d=0.77[0.67,0.87]$ for Prolific, $t(798)=12.49$, $p<.001, d=0.54[0.44,0.64]$ for MTurk.

Hypothesis 1A (combined samples). The key test is whether individuals overestimated the effect of payment on self-reported willingness to donate (see Table 4 for raw means). We compared Paid vs. Unpaid between the Self and Others conditions. In a one-sample $t$-test we found support for a discrepancy, $t(1598)=33.85, p<.001, d=0.85[0.79,0.90]$ (see Table 5 and Figure 2 for results by sample). Overall, participants overestimated the effect of payment by $M=$ $12 \%$, and the one-sample $t$-test against $\mu=0$ for overestimation was $t(1597)=23.1, p<.0001, d$ 
$=0.58[0.53,0.63]$. Testing the distribution of overestimation directly against the distribution of willingness was not possible because these data are from different participants (and willingness was binary for each payment condition). Also consistent with the original article, the effect of payment was smaller for the self than in estimates for others, Self: $t(1597)=9.14, p<.001, d=$ $0.23[0.18,0.28]$, Others: $t(1597)=33.89, p<.001, d=0.85[0.79,0.91]$.

Table 5

Overestimation of Self-Interest in Study 1

\begin{tabular}{lccccccr}
\hline & & & & & & $95 \%$ & \\
Sample & $n$ & $M$ & $S D$ & $t$ & $d$ & $C I$ & Interpretation \\
\hline MTurk & 799 & $12.2 \%$ & 20.8 & 16.6 & 0.59 & {$[0.51,0.66]$} & Signal Same Direction \\
Prolific & 799 & $11.8 \%$ & 20.8 & 16.1 & 0.57 & {$[0.49,0.64]$} & Signal Same Direction \\
\hline Combined & 1598 & $12.0 \%$ & 20.8 & 23.1 & 0.58 & {$[0.53,0.63]$} & Signal Same Direction \\
\hline
\end{tabular}

Note. Overestimation $M$ was calculated by taking the mean difference of estimates between paid and unpaid conditions and subtracting the mean difference between paid and unpaid conditions of selfreported willingness. The one-sample $t$-tests were against $M=0$ (equivalence). All $p$ s $<.0001$. The interpretation is based on (LeBel et al., 2019), and the size of the effects could not be precisely compared to the original due to missing information. 
Figure 2

Histogram of Overestimation of Self-Interest in Study $1(N=1598)$
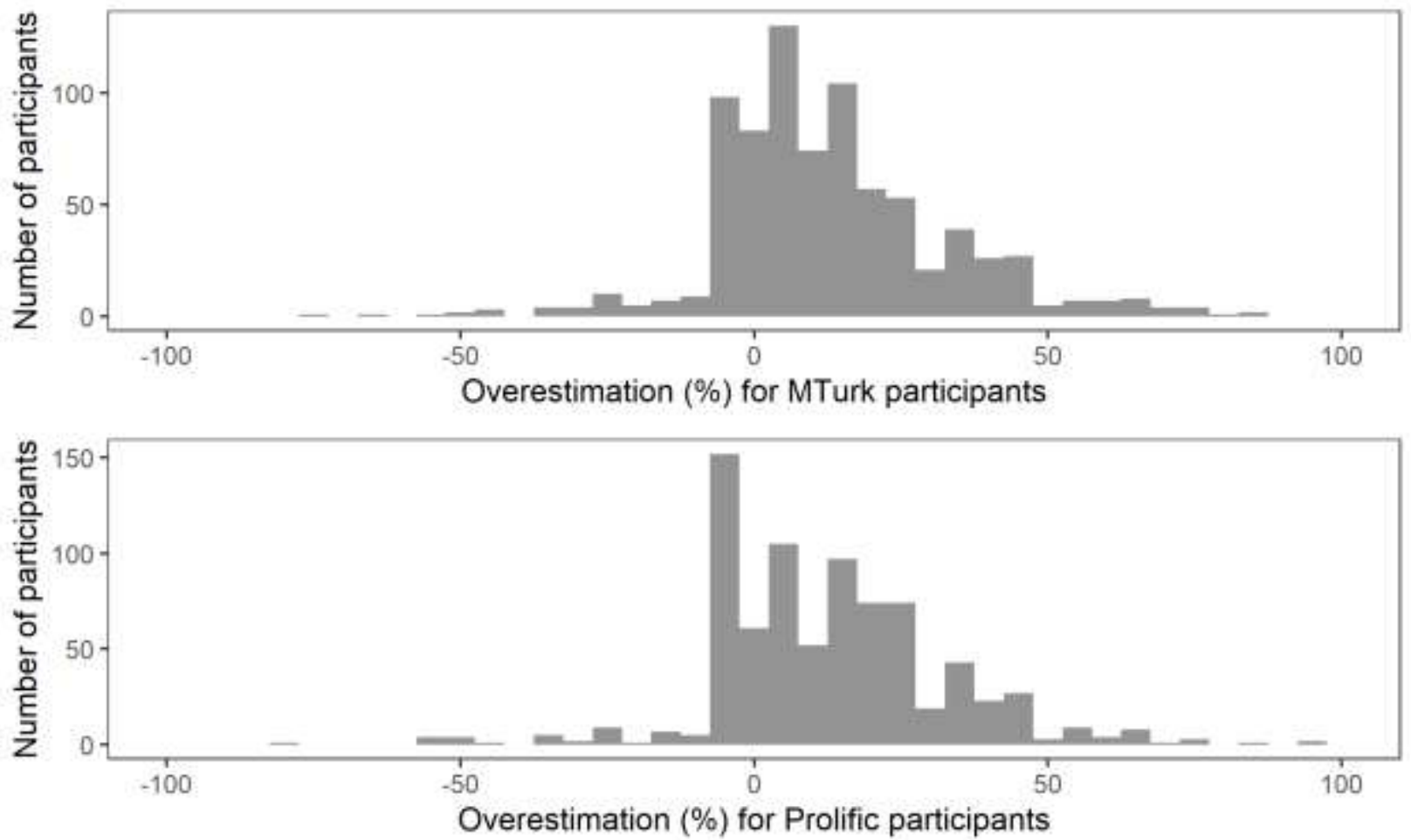

Hypothesis $1 B$ (combined samples). Whether the paid vs. unpaid difference in willingness to donate was related to the estimation of others was examined with a $t$-test. Participants who were willing to donate in the paid but not unpaid condition were labeled price-sensitive, and participants whose willingness did not change on payment (or changed in the other direction) were labeled price-insensitive. Price sensitivity predicted higher estimates of self-interest in others, $t(1596)=-7.67, p<.0001, d=0.19[0.14,0.24]$. See Table S3 for the tests by sample.

Order effects. Study 1 overestimation was not different based on the order of first completing Study 1 vs. Study $4, t(189)=-0.56, p=.58,95 \%$ CI of the overestimation difference $-8.89,4.95$.

\section{Summary}


Study 1 provided evidence for an overestimation of financial self-interest in willingness to donate blood. Consistent with the original study, payment increased both actual and estimated willingness to donate, and sensitivity to payment predicted higher estimates of self-interest in others. Hypotheses 1A and 1B were both supported with moderate effect sizes. However, the design of Study 1 has an additional confound in that participants were asked to estimate others' donation, not estimate others' self-reported willingness to donate; asking for estimations of the latter could have yielded more accurate estimates. Below, we examined self-interest in an unrelated paradigm about smokers to address this and two other potential issues in Study 1.

\section{Study 4}

In Study 4, smokers and nonsmokers indicated their preferences for eight cigarette taxes and smoking restrictions, and estimated the preferences of smokers and nonsmokers addressing three potential limitations in Study 1. First, some individuals may not find financial incentives relevant for prosocial behaviors like blood donation. When the true effect of self-interest could be null or inconsistent, overestimation could be less informative. In contrast, Study 4 uses a scenario with a vested interest that impacts people's attitudes: smoking status. This may provide a more stringent test of overestimation because there is less room to overestimate a positive compared to null effect of self-interest. Second, this design aligns the self-report and the estimates such that others are estimating the same behavior (self-reported policy endorsement). Third, the 1998 study only measured smoking as yes or no, similar to Study 1 only having two conditions (paid and unpaid). In an extension in the MTurk sample, we introduced a five-item ordinal measure of smoking frequency to test for a more granular relationship between selfinterest and policy preferences. 


\section{Method}

Participants were told that the study was to investigate smokers' and nonsmokers' attitudes toward smoking-related policies and were then randomized to the conditions below (see Table 3 to compare the method with the original, and Table S2 for the exact text).

\section{Manipulation 1: Self or Others' Attitudes}

Participants were randomized to one of two main conditions. In the Self group, participants indicated their own smoking status and their own attitudes towards policies. In the Others group, participants only estimated what percentage of others would support the policy based on others' smoking status.

\section{Manipulation 2: Smoking Status (MTurk Sample Only)}

This extension is about a more precise measurement of smoking status. In the Prolific sample and the original study in the own-attitudes condition, participants reported their smoking status as "yes" or "no". In the MTurk sample only, participants were randomized either to that binary choice or to a five-item ordinal scale: 1 (nonsmokers: never smoked for more than 6 months), 2 (former smokers: not smoking currently, but having smoked for more than 6 months), 3 (light smokers: <10 cigarettes per day), 4 (moderate smokers: 10-20 cigarettes per day), or 5 (heavy smokers: $>20$ cigarettes per day). Similarly, in the Prolific sample and the original in the others-attitudes condition, participants estimated the policy support of others based on others' smoking status as "smoker" or "nonsmoker", but the MTurk sample only, participants were randomized either to that same design or to estimate others' policy preferences for each of the five categories above.

\section{Measures}


Participants rated attitudes towards eight smoking-related policies: (1) increased tax on cigarettes; (2) a complete ban on cigarette advertisement; (3) a complete ban on smoking in public spaces, and restrictions on smoking in (4) restaurants, (5) workplaces, (6) buses and trains, (7) airplanes, and (8) hotels and motels. Participants in the Self condition rated the items support, oppose, or no opinion. For means and tests, the answers were coded 0 (oppose; $12.3 \%$ ), 0.5 (no opinion; 5.5\%), 1 (support; 82.1\%). See below for a robustness check excluding "no opinion" values; the main results are consistent.

\section{Results}

Participants in the Others condition estimated support for each smoking policy from 0 $100(\%)$ for both smokers and nonsmokers (Table 6 and Figure 3). The mean estimates across policies are shown in Figure 3. 
Table 6

Policy Attitudes by Smoking Status in Study 4

\begin{tabular}{|c|c|c|c|c|c|}
\hline & & \multicolumn{2}{|c|}{ Self } & \multicolumn{2}{|c|}{ Others (Estimated) } \\
\hline \multirow{3}{*}{\multicolumn{2}{|c|}{$\begin{array}{l}n \text { MTurk } \\
n \text { Prolific }\end{array}$}} & Smokers & Nonsmokers & Smokers & Nonsmokers \\
\hline & & 58 & 149 & 206 & 206 \\
\hline & & 83 & 317 & 399 & 399 \\
\hline \multirow{3}{*}{$\begin{array}{l}\text { Policy } \\
\text { Increase cigarette } \\
\text { taxation }\end{array}$} & Sample & \multicolumn{2}{|c|}{$\%$} & \multicolumn{2}{|c|}{$\mathrm{M}(S D)$} \\
\hline & MTurk & 25.9 & 74.2 & $12.3(20.6)$ & $77.5(29.5)$ \\
\hline & Prolific & 33.1 & 83.6 & $13.5(16.6)$ & $79.2(22.6)$ \\
\hline \multirow{2}{*}{ Ban cigarette ads } & MTurk & 66.4 & 76.2 & $40.2(31.1)$ & $77.2(27.2)$ \\
\hline & Prolific & 71.1 & 90.7 & $46.5(30.2)$ & $81.1(21.3)$ \\
\hline \multirow{2}{*}{$\begin{array}{r}\text { Ban smoking in } \\
\text { public places }\end{array}$} & MTurk & 33.6 & 79.5 & $18.8(23.5)$ & $76.6(25.9)$ \\
\hline & Prolific & 44.0 & 80.3 & $19.1(21.9)$ & $77.3(23.6)$ \\
\hline \multirow{2}{*}{$\begin{array}{l}\text { Restrict smoking in } \\
\text { restaurants }\end{array}$} & MTurk & 72.4 & 91.6 & $44.3(31.6)$ & $88.0(20.4)$ \\
\hline & Prolific & 86.1 & 97.8 & $48.4(30.2)$ & $92.2(15.1)$ \\
\hline \multirow{2}{*}{$\begin{array}{l}\text { Restrict smoking in } \\
\text { workplaces }\end{array}$} & MTurk & 72.4 & 89.9 & $43.1(31.6)$ & $85.6(22.3)$ \\
\hline & Prolific & 80.7 & 96.1 & $40.8(29.4)$ & $88.6(18.3)$ \\
\hline \multirow{2}{*}{$\begin{array}{l}\text { Restrict smoking on } \\
\text { buses and trains }\end{array}$} & MTurk & 88.8 & 95.3 & $51.4(32.4)$ & $89.6(19.6)$ \\
\hline & Prolific & 88.6 & 97.6 & $50.2(31.2)$ & $92.6(13.9)$ \\
\hline \multirow{2}{*}{$\begin{array}{l}\text { Restrict smoking on } \\
\text { airplanes }\end{array}$} & MTurk & 91.4 & 95.6 & $63.3(34.1)$ & $91.5(20.1)$ \\
\hline & Prolific & 90.4 & 98.7 & $60.3(34.1)$ & $94.9(14.2)$ \\
\hline \multirow{2}{*}{$\begin{array}{l}\text { Restrict smoking in } \\
\text { hotels \& motels }\end{array}$} & MTurk & 56.9 & 86.9 & $32.0(27.2)$ & $84.6(22.6)$ \\
\hline & Prolific & 69.3 & 95.1 & $38.9(28.0)$ & $88.0(17.1)$ \\
\hline \multirow{2}{*}{ Total $(M)$} & MTurk & 63.5 & 86.2 & $38.2(33.0)$ & $83.9(23.6)$ \\
\hline & Prolific & 55.3 & 92.5 & $39.7(31.8)$ & 86.7 (19.6) \\
\hline
\end{tabular}

Note: Total rows were calculated with the means of all eight policies within participants and then the mean across participants. 
Figure 3

Estimated Policy Support by Others' Smoking Status ( $\mathrm{N}=965)$

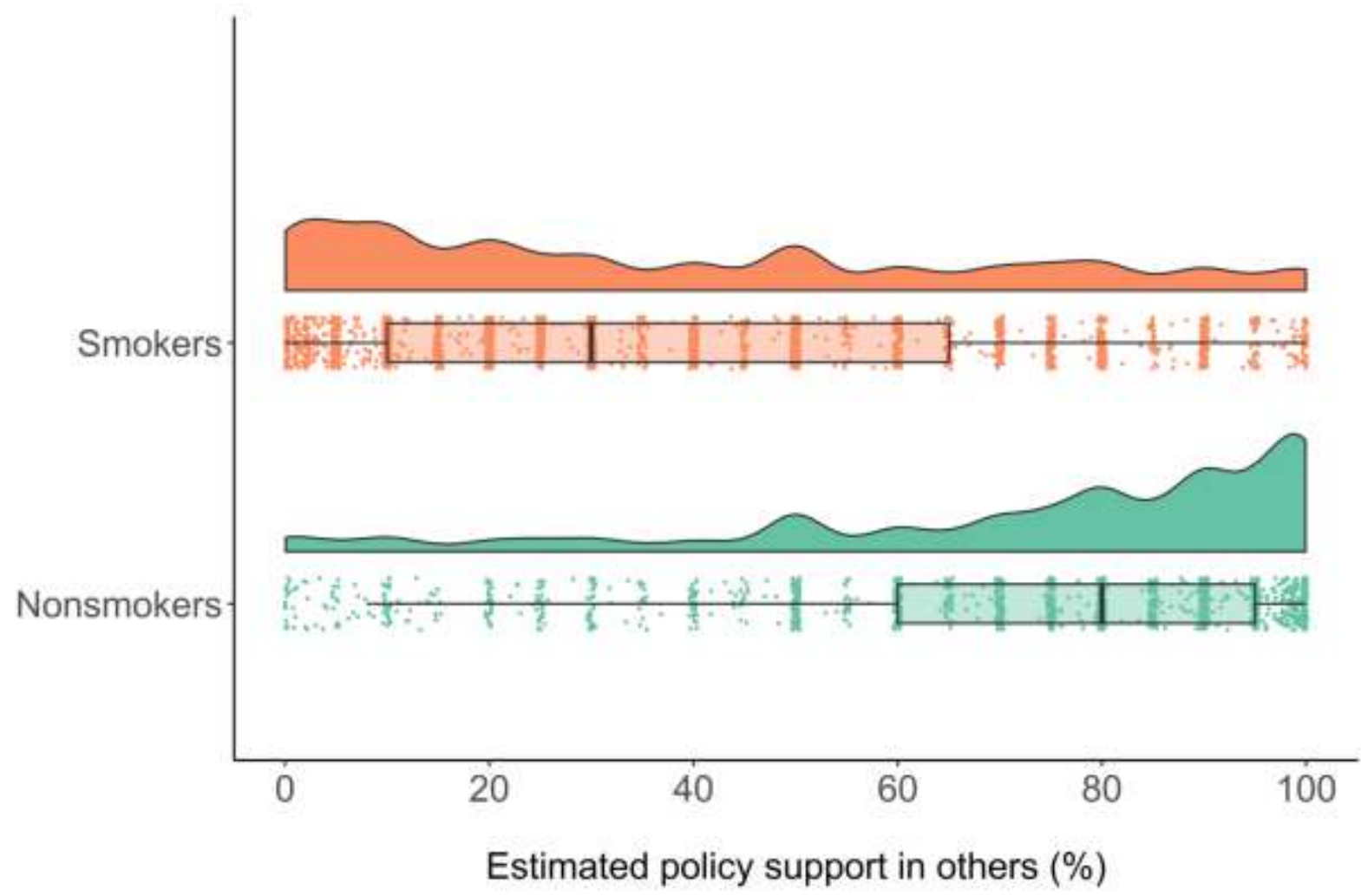

Note. Shown as raincloud plots (Allen et al., 2019). The boxes indicate the interquartile range of that row $(25-75 \%)$, the whiskers the values within 1.5 times that range, and the vertical black lines the medians.

Hypothesis 4A. For each policy, $t$-tests were conducted between the support rates for smokers and nonsmokers (Table S4). Nonsmokers were more supportive than smokers towards the policies, consistent with the original article. Of the $16 t$-tests (eight policies per study), 13 were significant in the hypothesized direction. This suggests that the policies were interpreted as being negative for smokers. Note that there is no Hypothesis 3. Hypothesis 4 corresponds to Study 4, and this maintains continuity with the pre-registrations.

Hypothesis 4B: Overestimation. This is the key result in Study 4. First, we conducted one-sample $t$-tests on the replications to compare the actual vs. estimated differences between smokers and nonsmokers. We replicated the discrepancies between self and others in all policies 
in both samples: estimated self-interest was higher than actual self-interest for all policies (all $p s$ $<.001)($ Table S5).

Overestimation of self-interest was measured by subtracting the estimate for smokers from nonsmokers within each policy, and then taking the mean of all policies within participants to yield an estimate of self-interest. From this value, we subtracted the actual discrepancy between smokers and nonsmokers from the other condition of the study, which was $M=27.1 \%$. Overall, participants overestimated the self-interest of smokers by $M=19.5 \%$ (see Table 7 and Figure 4 for the results by sample). The one-sample $t$-test against $\mu=0$ for overestimation in both samples combined was $t(604)=19.9, p<.0001, d=0.81[0.72,0.90]$. As a separate robustness check, the "no opinion" ratings (5.5\% of responses) were excluded and these calculations re-run. The result also showed overestimation across both samples $(M=12 \%)$ and the interpretation in the Discussion remains consistent with either effect size. Note that policy endorsement was generally high, which could represent a possible ceiling effect.

Order effects. Study 4 overestimation was not different based on the order of first completing Study 1 vs. Study 4, $t(788)=1.68, p=.09,95 \%$ CI of the overestimation difference $0.40,5.37$. 
Table 7

Overestimation of Self-Interest in Study 4

\begin{tabular}{lccccccc}
\hline Sample & $M$ & $S D$ & $d f$ & $t$ & $d$ & $95 \% C I$ & Interpretation \\
\hline MTurk & 18.5 & 24.9 & 205 & 10.7 & 0.75 & {$[0.59,0.90]$} & Signal Same Direction \\
Prolific & 19.9 & 23.7 & 398 & 16.8 & 0.84 & {$[0.73,0.96]$} & Signal Same Direction \\
\hline Combined & 19.5 & 24.1 & 604 & 19.9 & 0.81 & {$[0.72,0.90]$} & Signal Same Direction \\
\hline
\end{tabular}

Note. Overestimation was calculated by subtracting the estimate for smokers from nonsmokers within each policy, and then taking the mean of all policies within participants to yield estimated self-interest. From this value, we subtracted the actual discrepancy between smokers and nonsmokers from the selfreported condition. The one-sample $t$-tests were against $M=0$ (equivalence); both $p$ s $<.0001$. The lower $d f$ for MTurk is because of randomization to the extension. The interpretation is based on (LeBel et al., 2019), and the size of the effects could not be precisely compared to the original due to missing information.

Figure 4

Histogram of Overestimation of Self-Interest in Study $4(\mathrm{~N}=605)$
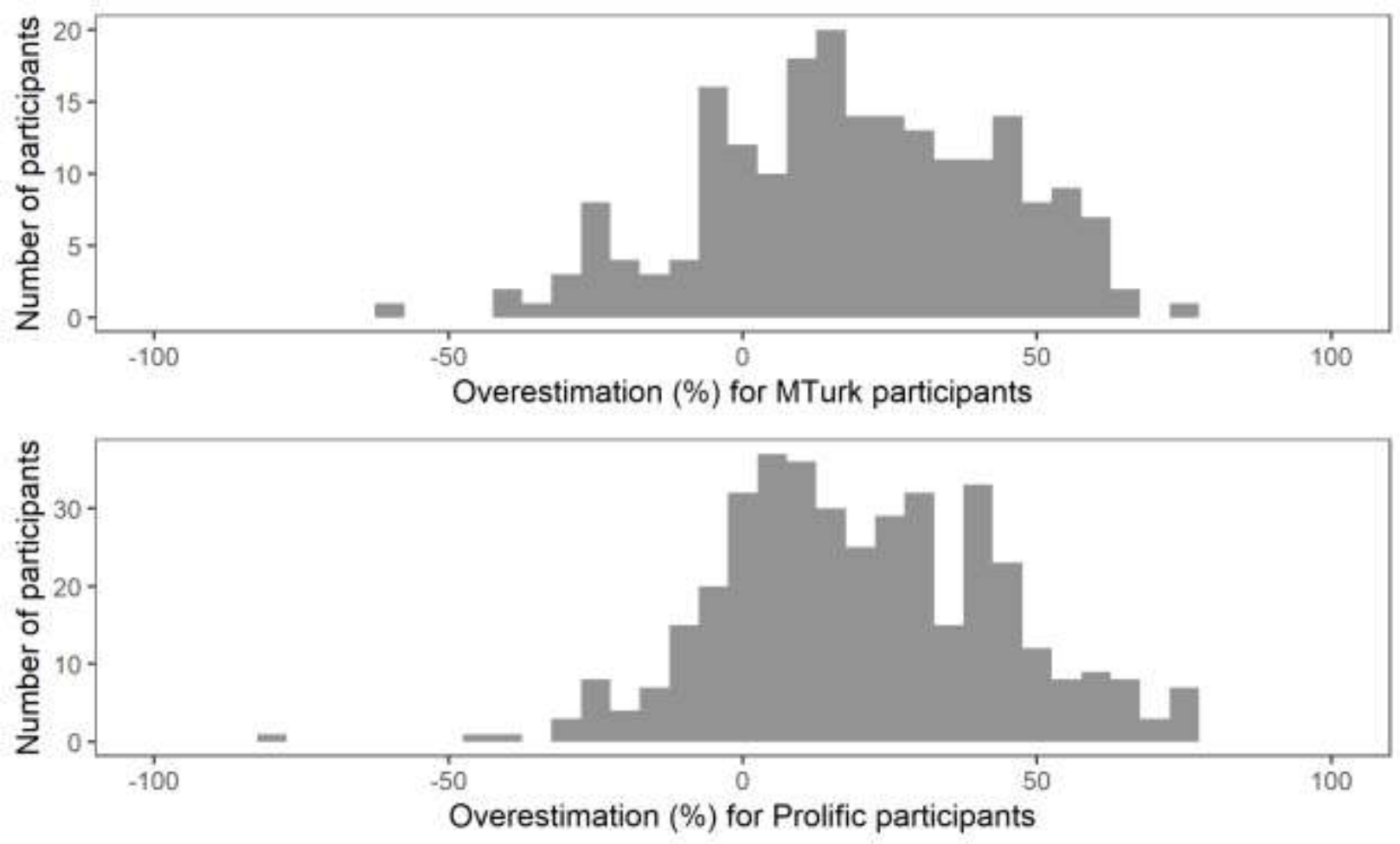

Extension: Smoking Status Measure (MTurk Sample) 
An ordinal smoking status measure was introduced for a random half of the MTurk sample to help test how self-interest impacts actual and estimated attitudes towards smoking policies. Actual and estimated policy support by ordinal smoking status is shown in Table 8 .

\section{Table 8}

Extension: Actual and Estimated Policy Support (\%) by Ordinal Smoking Status (MTurk Only, N $=377)$

\begin{tabular}{|c|c|c|c|c|c|c|c|c|c|c|}
\hline \multirow[b]{2}{*}{$n$} & \multicolumn{2}{|c|}{ Non-smokers } & \multicolumn{2}{|r|}{ Former } & \multicolumn{2}{|r|}{ Light } & \multicolumn{2}{|c|}{ Moderate } & \multicolumn{2}{|r|}{ Heavy } \\
\hline & 105 & 176 & 62 & 175 & 15 & 174 & 18 & 173 & 6 & 174 \\
\hline$\%$ & Self & Others & Self & Others & Self & Others & Self & Others & Self & Others \\
\hline Policy & $M$ & $M(S D)$ & $M$ & $M(S D)$ & $M$ & $M(S D)$ & $M$ & $M(S D)$ & $M$ & $M(S D)$ \\
\hline Tax & 76.7 & $77.3(29.3)$ & 70.2 & $60.9(33.7)$ & 36.7 & $22.2(27.6)$ & 30.6 & $14.8(24.0)$ & 33.3 & $11.2(24.4)$ \\
\hline Ads & 76.7 & $76.9(31.1)$ & 79.8 & $67.6(33.2)$ & 50.0 & $40.0(32.0)$ & 88.9 & $34.6(31.4)$ & 66.7 & $29.5(32.0)$ \\
\hline Public & 85.7 & 79.4 (29.7) & 64.5 & $63.9(33.0)$ & 36.7 & $29.6(31.4)$ & 33.3 & $21.9(27.7)$ & 66.7 & $15.8(26.4)$ \\
\hline Resta. & 97.1 & $87.6(25.8)$ & 91.9 & 76.7 (30.4) & 66.7 & $50.9(34.2)$ & 77.8 & $43.0(33.0)$ & 100 & $31.2(31.8)$ \\
\hline Work & 93.8 & $86.3(25.7)$ & 90.3 & 72.7 (32.6) & 73.3 & 46.5 (33.9) & 88.9 & $37.0(31.8)$ & 50.0 & $25.8(30.3)$ \\
\hline Bus & 96.7 & $86.0(28.0)$ & 96.8 & $75.0(32.3)$ & 73.3 & $55.0(35.1)$ & 88.9 & $45.8(34.2)$ & 100 & $34.2(33.5)$ \\
\hline Plane & 96.7 & $89.5(26.0)$ & 99.2 & $80.3(32.1)$ & 73.3 & $63.6(35.0)$ & 94.4 & $56.9(36.1)$ & 83.3 & $47.0(37.1)$ \\
\hline Hotel & 93.3 & $84.1(28.8)$ & 84.7 & $71.0(33.1)$ & 76.7 & $41.7(32.7)$ & 77.8 & $32.3(30.0)$ & 66.7 & $21.7(27.2)$ \\
\hline Total $(M)$ & 89.6 & $83.40(28.5)$ & 84.7 & $71.0(33.1)$ & 60.8 & $43.7(35.1)$ & 72.6 & $35.8(33.5)$ & 70.8 & $27.1(32.3)$ \\
\hline
\end{tabular}

The rarity of light $(n=15)$, moderate $(n=18)$, and heavy $(n=6)$ smokers meant there was not enough power for inferential tests on actual vs. estimated policy support in the extension. However, visual analysis suggests that overestimation may be most pronounced when individuals consider others with stronger vested interests (here: more frequent smokers). For 
example, the actual policy support of moderate smokers was $M=72 \%$ and heavy smokers $M=$ $71 \%$, but others sharply underestimated those values (moderate smoker support estimated at $M=$ 36\%; heavy smokers $M=27 \%$ ). Any overestimation effect in these groups should be treated with special caution due to the small samples and the analytic choice to use one-sample t-tests against a certain value, since this does not include variance underlying that value's estimate.

\section{Extension: Communalism (Prolific Sample)}

Hypothesis 2 informs whether the individual difference of communalism is associated with prosocial behavior, estimates for others, and the degree of overestimation (Prolific sample only).

Prosocial behavior. In Study 1, correlations suggested that more communal individuals were more likely to donate in both the paid, $r(797)=.16, p<.001$, and unpaid conditions, $r(797)$ $=.25, p<.001$ (H2A; point-biserial). In Study 4, communality appeared unrelated to support for the smoking restrictions for smokers, $r(158)=.03, p=.72$, and nonsmokers, $r(455)=.02, p=$ $.73(H 2 B ;$ Pearson's $r)$.

Estimates for others. Correlations suggested that more communal individuals gave higher estimations of others donating blood in the paid, $r(797)=.15, p<.001$, and unpaid conditions, $r(797)=.16, p<.001(H 2 C$; Pearson's $r)$. In Study 4, communality seemed unrelated to policy estimations for smokers, $r(397)=.04, p=.48$, and estimations for nonsmokers, $r(397)=.08, p=$ $.09(H 2 D$; Pearson's $r)$.

Overestimation. The key test in this extension was whether more communal individuals would overestimate less; that is, whether their estimates would be more accurate than less communal individuals. Communalism was unrelated to overestimation using Pearson's $r$ correlation in Study 1, $r(797)=-.02, p=.53(H 2 E)$, or in Study 4, $r(397)=.02, p=.72(H 2 F)$. In 
exploratory correlations between overestimation in both studies with age, social class, gender, skill in English, and participating carefully, most effects were null or small except for younger people overestimating more in Study $1, r(1596)=-.23, p<.0001$. This is consistent with younger people being more sensitive to payment in Study 1 (younger people showed more selfinterest; correlation between age and Study 1 self-interest $r(1596)=-.17, p<.0001)$.

\section{General Discussion}

The results in both samples and both studies strongly supported the original findings. Individuals overestimated the impact of self-interest on intentions to donate blood, and also how much smoking status determined support of smoking regulations $(d s>0.58)$. The overestimation effects may have been smaller than the original paper, but original effect sizes could not be precisely calculated because the variances were not reported. Any discrepancies in effect size from the original could be attributed to noise from their small sample size, an estimation error due to the lack of their reported statistics, or differences in the context or manipulation strength. For example, because of currency inflation, \$15 was less incentive in 2019 than in 1998, which could lead to smaller perceived incentive in the replication.

In Study 4, the original study did not find significant effects of self-interest for four out of eight policies in self-ratings, perhaps due to lack of statistical power. We found support for selfinterest effects for 13 out of 16 tests (smokers endorsed the policies less; eight policies in two samples), with particularly large effects in the MTurk sample (Table S4). Replications often focus on replicating the significant original effects, but finding support for non-significant effects in the original article is also informative (Chandrashekar, Yeung, Yau, Feldman, \& Chan, 2020; LeBel et al., 2019). Here, these additional findings suggest strong generalizability of the overestimation effect across different types of smoking policies (e.g., restriction and taxation). 
To evaluate a more granular measure of self-interest, a random half of participants in a Study 4 extension gave responses for five categories of smoking frequency rather than just two. The ordinal smoking status scale did not yield enough smokers within each category for inferential tests. However, it appears from visual analysis that overestimation may be most pronounced when individuals consider others with stronger vested interests. In the extension, that pattern could be partially due to an expectancy effect. Participants may have assumed that being asked about multiple categories of smoker implied that each category would be different in policy support.

The other extension investigated individual differences that predict overestimation. The social norm in Western individualistic cultures that self-interest powerfully determines behavior may be relevant to overestimation (Ratner \& Miller, 2001). Beliefs about self-interest may become self-fulfilling by influencing social institutions and individual decision-making processes, which in turn could reinforce the original idea of self-interested human nature. Therefore, communalism was tested in predicting donation, policy support, estimates of each, and overestimation of self-interest. As expected, communality was positively associated with more prosocial behavior and endorsement of smoking restrictions, and was also positively associated with higher estimates of others' prosociality in both studies. However, we found no support for a relationship between overestimation and communality in either study. Exploratory correlations with other demographics revealed mostly null effects, but being younger was associated with more overestimation in Study 1, perhaps because younger individuals have less money. It remains valuable to identify other individual differences associated with overestimation. 


\section{Limitations and Future Directions}

\section{Alternative Explanations}

Self-reported willingness to donate blood or endorse smoking policies is not equivalent to objective behaviors like blood donation or voting. The main narrative in this paper is that people over-estimate others' self-interest, but the results are also consistent with the pattern that such estimates are accurate and that self-reported willingness is inaccurate; that in actual behavior people would manifest more self-interest than they expect or are willing to report. Further studies with observed behavior would be valuable for testing this account.

The experimental paradigms were copied from the original manuscript and not validated before testing the hypotheses. The vignettes and manipulations might have confounds or unknown effects orthogonal to the theory and predictions used here. Additionally, the participants were only given very sparse information about the targets, e.g., that they were smokers or nonsmokers. This could have created an expectancy effect or at the least an ecologically unusual focus on a single attribute when predicting how individuals would evaluate policies. By failing to provide rich, complex targets with varied mental experiences, the paradigms here may have encouraged individuals to focus on external behaviors like smoking, which could alter attributions and perceived self-interest (Vuolevi \& Van Lange, 2009). Future studies could consider richer, more life-like vignettes, or paying participants for their accuracy.

\section{Attitudes versus Behaviors}

The original article and the current replications hinge on outcomes that may be better characterized as intentions rather than behaviors. This is important because self-interest may predict behavior better than attitudes (Ratner \& Miller, 2001). For instance, one study found that people who owned property or had school-age children did not oppose school busing policy 
more than those without material stake in the policy, but they were much more likely to join antibusing organizations (Green \& Cowden, 1992). Another key paper found that people overestimated their likelihood of acting generously but accurately predicted other's behaviors (Epley \& Dunning, 2000). Perceived self-interest may be higher when people face immediate, concrete outcomes (Boninger et al., 1995), and people's sensitivity to their self-interest increases after self-interest is made salient (Ratner \& Miller, 2001). Thus, future research on the overestimation of self-interest could focus on consequential behaviors rather than hypotheticals. This could help resolve conflicting findings (Epley \& Dunning, 2000; Vuolevi \& Van Lange, 2009) and provide better generalizability to real-world contexts.

\section{Constraints on Generality}

The current findings and their interpretation are based on sampling and measurement choices that limit their generalizability as with any study (Simons, Shoda, \& Lindsay, 2017). Sample. The participants were recruited from MTurk (USA) and Prolific (UK). Both samples were more representative of their countries than university student samples, but the results may have limited generalizability to populations that are not Western, Educated, Industrialized, Rich, and Democratic (Cheon, Melani, \& Hong, 2020; Henrich, Heine, \& Norenzayan, 2010). In particular, overestimation of others' self-interest may be inflated by social norms of self-interest in individualistic societies. There is a strong need for studies on overestimation of others' self-interests in non-Western samples. Cross-cultural, multi-lab studies such as through consortia like the Psychological Science Accelerator (Moshontz et al., 2018) could replicate and extend this phenomenon particularly in collectivistic cultures with weaker norms of self-interest. 
Method, Measures, and Contexts. We closely replicated the original studies across two medical topics — blood donation and smoking — measuring attitudes and intentions but not objective behavior. Our results appeared to contradict Epley and Dunning (2000), but were consistent with Vuolevi and Van Lange (2009), which both measured behavior. These discrepancies could be due to differences in measures or topics. Future replication studies could focus on consequential behaviors and consider other decision contexts such as financial or environmental decisions.

Overestimating self-interest may also be higher when participants lack information about the other people making decisions. When study vignettes refer to unspecified others and only provide limited information, e.g., the decision maker is a smoker or not, participants may base their estimates on generalized perceptions of norms of self-interest (Vuolevi \& Van Lange, 2009). Therefore, future studies could investigate contexts in which participants have more specific information or richer interactions with the estimation targets.

Additionally, there was a possible ceiling effect in self-reported policy endorsement in Study 4. This could have led to an artificially smaller difference between estimates and selfreported preferences due to the specific policies. That is, for a different set of policies, one might observe even more overestimation without this restriction in range.

\section{Conclusion}

We presented two well-powered, pre-registered studies across two samples that both successfully replicated the original Studies 1 and 4 by Miller and Ratner (1998) using online surveys of U.S. and U.K. residents. Individuals strongly overestimated the power of self-interest on others' blood donation willingness and smoking policy preferences. Self-interest may act as a self-fulfilling social norm (Ferraro et al., 2005), and therefore overestimation has broad 
implications for cooperation within and between social groups and institutions. Across a society, perceived self-interest is important because it could affect support for laws against individual interests such as on environmental issues. Our results that people overestimate self-interest could potentially help reduce demagogy appealing to individual interests. We encourage future studies to further investigate the generalizability and boundary conditions of the overestimation effect (Simons et al., 2017).

\section{Open Practices}

Open data, code, materials, and the 2019 pre-registrations are available at https://osf.io/57mdc/

\section{References}

Agnew, R. (2014). Social concern and crime: Moving beyond the assumption of simple selfinterest. Criminology, 52(1), 1-32. doi: 10.1111/1745-9125.12031

Allen, M., Poggiali, D., Whitaker, K., Marshall, T. R., \& Kievit, R. A. (2019). Raincloud plots: a multi-platform tool for robust data visualization. Wellcome Open Research, 4, 63. doi: 10.12688/wellcomeopenres.15191.1

Barkow, J. H., Cosmides, L., \& Tooby, J. (1995). The adapted mind: Evolutionary psychology and the generation of culture. Oxford University Press, USA.

Batson, C. D., \& Powell, A. A. (2003). Altruism and prosocial behavior. In I. B. Weiner (Ed.), Handbook of Psychology (Vol. 1, p. 267). Hoboken, NJ, USA: John Wiley \& Sons, Inc. doi: 10.1002/0471264385.wei0519

Berinsky, A. J., Huber, G. A., \& Lenz, G. S. (2012). Evaluating online labor markets for experimental research: Amazon.com's Mechanical Turk. Political Analysis, 20(3), 351-368. 
doi: $10.1093 / \mathrm{pan} / \mathrm{mpr} 057$

Besley, T., \& Ghatak, M. (2018). Prosocial motivation and incentives. Annual Review of Economics, 10(1), 411-438. doi: 10.1146/annurev-economics-063016-103739

Boninger, D. S., Krosnick, J. A., \& Berent, M. K. (1995). Origins of attitude importance: Selfinterest, social identification, and value relevance. Journal of Personality and Social Psychology, 68(1), 61-80. doi: 10.1037/0022-3514.68.1.61

Caplan, B. (2011). The myth of the rational voter: Why democracies choose bad policies. Princeton University Press.

Chandrashekar, P., Yeung, S. K., Yau, K. C., Feldman, G., \& Chan, C. (2020). Free-will and self-other asymmetries in perceived bias and shortcomings: Replications of the Bias Blind Spot and extensions linking to free will beliefs (pre-print). doi:

10.13140/RG.2.2.19878.16961/2

Cheon, B. K., Melani, I., \& Hong, Y.-Y. (2020). How USA-centric is psychology? An archival study of implicit assumptions of generalizability of findings to human nature based on origins of study samples. Social Psychological and Personality Science. doi:

$10.1177 / 1948550620927269$

Clark, M. S., Oullette, R., Powell, M. C., \& Milberg, S. (1987). Recipient's mood, relationship type, and helping. Journal of Personality and Social Psychology, 53(1), 94-103. doi: $10.1037 / 0022-3514.53 .1 .94$

Cohen, G. L. (2003). Party over policy: The dominating impact of group influence on political beliefs. Journal of Personality and Social Psychology, 85(5), 808-822. doi: 10.1037/00223514.85.5.808

Critcher, C. R., \& Dunning, D. (2011). No good deed goes unquestioned: Cynical reconstruals 
maintain belief in the power of self-interest. Journal of Experimental Social Psychology, 47(6), 1207-1213. doi: 10.1016/j.jesp.2011.05.001

Darke, P. R., \& Chaiken, S. (2005). The pursuit of self-interest: self-interest bias in attitude judgment and persuasion. Journal of Personality and Social Psychology, 89(6), 864-883. doi: $10.1037 / 0022-3514.89 .6 .864$

Epley, N., \& Dunning, D. (2000). Feeling "holier than thou": are self-serving assessments produced by errors in self- or social prediction? Journal of Personality and Social Psychology, 79(6), 861-875. doi: 10.1037/0022-3514.79.6.861

Evans, A. M., \& Krueger, J. I. (2016). Bounded prospection in dilemmas of trust and reciprocity. Review of General Psychology, 20(1), 17-28. doi: 10.1037/gpr0000063

Feldman, G. [@giladfeldman]. (2020, January 2). (Twitter prediction markets \#5) Actual versus assumed power of self-interest. Miller \& Ratner (1998) Experiment 1 Replication info. https://twitter.com/giladfeldman/status/1212585851701661699

Felin, T., \& Foss, N. J. (2009). Social reality, the boundaries of self-fulfilling prophecy, and economics. Organization Science, 20(3), 654-668. doi: 10.1287/orsc.1090.0431

Ferraro, F., Pfeffer, J., \& Sutton, R. I. (2005). Economics language and assumptions: How theories can become self-fulfilling. AMRO, 30(1), 8-24. doi: 10.5465/amr.2005.15281412

Force, P. (2003). Self-interest before Adam Smith: A genealogy of economic science. Cambridge University Press.

Gardner, D. M., \& Ryan, A. M. (2020). What's in it for you? Demographics and self-interest perceptions in diversity promotion. The Journal of Applied Psychology. doi: 10.1037/ap10000478

Ghoshal, S., \& Moran, P. (1996). Bad for practice: A critique of the transaction cost theory. 
AMRO, 21(1), 13-47. doi: 10.5465/amr.1996.9602161563

Green, D. P., \& Cowden, J. A. (1992). Who protests: Self-interest and white opposition to busing. The Journal of Politics, 54(2), 471-496. doi: 10.2307/2132035

Hauser, D. J., \& Schwarz, N. (2016). Attentive Turkers: MTurk participants perform better on online attention checks than do subject pool participants. Behavior Research Methods, 48(1), 400-407. doi: 10.3758/s13428-015-0578-z

Henrich, J., Heine, S. J., \& Norenzayan, A. (2010). Most people are not WEIRD. Nature, 466(7302), 29. doi: 10.1038/466029a

John, L. K., Loewenstein, G., \& Prelec, D. (2012). Measuring the prevalence of questionable research practices with incentives for truth-telling. Psychological Science, 23(5), 524-532. doi: $10.1177 / 0956797611430953$

Jost, J. T., Banaji, M. R., \& Nosek, B. A. (2004). A decade of system justification theory: Accumulated evidence of conscious and unconscious bolstering of the status quo. Political Psychology, 25(6), 881-919. doi: 10.1111/j.1467-9221.2004.00402.x

Kagan, S. (1989). The limits of morality. Oxford University Press.

Kals, E., Maes, J., \& Becker, R. (2001). The overestimated impact of self-interest and the underestimated impact of justice motives. Trames, 5, 269.

Kool, V. K. (2008). The psychology of nonviolence and aggression (Vol. 235). New York, NY: Palgrave Macmillan.

LeBel, E. P., Vanpaemel, W., Cheung, I., \& Campbell, L. (2019). A brief guide to evaluate replications. Meta-Psychology, 3. doi: 10.15626/MP.2018.843

Le, B. M., Impett, E. A., Lemay, E. P., Jr, Muise, A., \& Tskhay, K. O. (2018). Communal motivation and well-being in interpersonal relationships: An integrative review and meta- 
analysis. Psychological Bulletin, 144(1), 1-25. doi: 10.1037/bul0000133

Litman, L., Robinson, J., \& Abberbock, T. (2017). TurkPrime.com: A versatile crowdsourcing data acquisition platform for the behavioral sciences. Behavior Research Methods, 49(2), 433-442. doi: 10.3758/s13428-016-0727-z

Mason, W., \& Suri, S. (2011). Conducting behavioral research on Amazon's Mechanical Turk. Behavior Research Methods, 44(1), 1-23. doi: 10.3758/s13428-011-0124-6

Miller, D. T. (1999). The norm of self-interest. The American Psychologist, 54(12), 1053-1060. doi: 10.1037/0003-066X.54.12.1053

Miller, D. T., \& Ratner, R. K. (1998). The disparity between the actual and assumed power of self-interest. Journal of Personality and Social Psychology, 74(1), 53-62. doi: $10.1037 / 0022-3514.74 .1 .53$

Moshontz, H., Campbell, L., Ebersole, C. R., IJzerman, H., Urry, H. L., Forscher, P. S., ... Chartier, C. R. (2018). The Psychological Science Accelerator: Advancing psychology through a distributed collaborative network. Advances in Methods and Practices in Psychological Science, 1(4), 501-515. doi: 10.1177/2515245918797607

Nelson, J. A. (2020). Economics for (and by) humans. Review of Social Economy, 1-14. doi: $10.1080 / 00346764.2020 .1792966$

Nosek, B. A., \& Lakens, D. (2014). Registered Reports: A method to increase the credibility of published results. Social Psychology, 45(3), 137-141. doi: 10.1027/1864-9335/a000192 Open Science Collaboration. (2015). Estimating the reproducibility of psychological science. Science, 349(6251), aac4716. doi: 10.1126/science.aac4716

Ostrom, E. (1990/2011). Governing the commons: The evolution of institutions for collective action. Cambridge, United Kingdom: Cambridge University Press. 
Palan, S., \& Schitter, C. (2018). Prolific.ac-A subject pool for online experiments. Journal of Behavioral and Experimental Finance, 17, 22-27. doi: 10.1016/j.jbef.2017.12.004

Ratner, R. K., \& Miller, D. T. (2001). The norm of self-interest and its effects on social action. Journal of Personality and Social Psychology, 81(1), 5-16. doi: 10.1037/0022-3514.81.1.5

Ratner, R. K., Zhao, M., \& Clarke, J. A. (2011). The norm of self-interest: Implications for charitable giving (Vol. 256, pp. 113-131). New York, NY, US: Psychology Press.

Simons, D. J., Shoda, Y., \& Lindsay, D. S. (2017). Constraints on generality (COG): A proposed addition to all empirical papers. Perspectives on Psychological Science, 12(6), 1123-1128. doi: $10.1177 / 1745691617708630$

Simpson, B., Irwin, K., \& Lawrence, P. (2006). Does a "norm of self-interest" discourage prosocial behavior? Rationality and quid pro quo in charitable giving. Social Psychology Quarterly, 69(3), 296-306. doi: 10.1177/019027250606900306

Van Boven, L., Ehret, P. J., \& Sherman, D. K. (2018). Psychological barriers to bipartisan public support for climate policy. Perspectives on Psychological Science, 13(4), 492-507. doi: $10.1177 / 1745691617748966$

Van Lange, P. A. M., \& Sedikides, C. (1998). Being more honest but not necessarily more intelligent than others: Generality and explanations for the Muhammad Ali effect. European Journal of Social Psychology, 28(4), 675-680. doi: 10.1002/(SICI)10990992(199807/08)28:4<675::AID-EJSP883>3.0.CO;2-5

Vuolevi, J. H. K., \& Van Lange, P. A. M. (2009). Beyond the information given: The power of a belief in self-interest. European Journal of Social Psychology, 7. doi: 10.1002/ejsp.711

Zwaan, R. A., Etz, A., Lucas, R. E., \& Donnellan, M. B. (2017). Making replication mainstream. The Behavioral and Brain Sciences, 1-50. doi: 10.1017/S0140525X17001972 


\section{Supplement}

Miller \& Ratner 1998 replications and extensions project

\section{Open Science Disclosures}

Data, Code, and Pre-registrations

https://osf.io/57mdc/

\section{Procedure and Data Disclosures}

Data Collection. Data collection was completed before analysis.

Conditions Reporting. All collected conditions are reported.

Data Exclusions. All exclusions are reported.

Variables Reporting. All measurements are reported and included.

\section{Deviations from pre-registration}

1. The .qsf (Qualtrics questionnaire export) was accidentally blank in the original preregistration for the Prolific sample, and the correct file was re-uploaded before the final submission.

2. Policy support was numerically coded no (0), no opinion (.5), and yes (1): this was not pre-registered. Another option would have been to excluded the no opinion responses. It was not specified in Miller and Ratner (1998) how "no opinion" was coded.

3. There are numerous analytic mistakes in the original pre-registrations, and much of the simulation and analysis code is not verifiable due to the reliance on manually entered numbers rather than functions with variables. In the final manuscript, the raw data was processed anew (see cleaning script) and all analyses were re-written. Because of this, the flow and content differ between the pre-registration and the final code. However, the fixity of the original hypotheses from the 1998 article ensured a tight set of research questions. All of the logic is consistent with the pre-registrations and all directional tests have the same direction and same basic method (most often $t$-tests).

4. An example of the issues with the original pre-registrations is that the original Results sections focused on self-other, paid-unpaid, and smoker-nonsmoker comparisons and tests. Some of this content was preserved in the current text and the Supplement, but none of these are the main theoretical point of the original article or its key hypotheses (H1A \& H4B), which is the overestimation of self-interest. Quantifying overestimation was somehow absent from the previous write-ups, perhaps because of the analytic challenge of computing it. This required some complex work in the $\mathrm{R}$ tidyverse such as multiple gather/spreads.

5. The pre-registrations from the two samples were independent and so all combined tests are new to this manuscript (not pre-registered). The logic of each test is consistent with the hypotheses and research question, and care was taken to minimize additional tests to control for false positives. Because all of the key results are $p<.0001$ in each sample and also combined, the decision to combine the samples for certain analyses for simplicity and ease of reading did not alter the interpretation. 
6. The MTurk and Prolific pre-registration supplements calculated power analyses based on estimated effect sizes for the original 1998 paper, but on closer examination, these calculations are not precise given that no variance was reported alongside the original means. Therefore, in the current manuscript no precise quantitative comparisons between original and replication effect sizes are given (LeBel et al., 2019).

7. The Prolific pre-registration supplement incorrectly reported on pp. 34 how many cases were missing for age. The correct answer is zero.

8. One participant was excluded for reporting an age of 11 . This exclusion was not preregistered; it was unexpected as the online panel participants were screened to be adults.

\section{Project Process Outline}

The current replication is part of a mass pre-registered replication project by the last author with the aim of revisiting well-known research findings in the area of social psychology and judgment and decision making and examining the reproducibility and replicability of these findings.

The current replication followed the same project outline as noted below. For each of the replication projects, researchers completed full pre-registrations, data analysis, and APA-style submission-ready reports. Authors independently reproduced the materials and designed the replication experiment, with a separate pre-registration document. The researchers then peerreviewed one another to try and arrive at the best possible design. Then, then lead and corresponding authors reviewed the integrated work and the last corresponding author made final adjustments and conducted the pre-registration and data collection.

The OSF page of the project contains two Qualtrics survey designs with pre-registration documents: one for each of the two teams. In the manuscript, we followed the most conservative of the pre-registrations. 
Figure S1

Flow Chart of JDM Replication-Extension Project

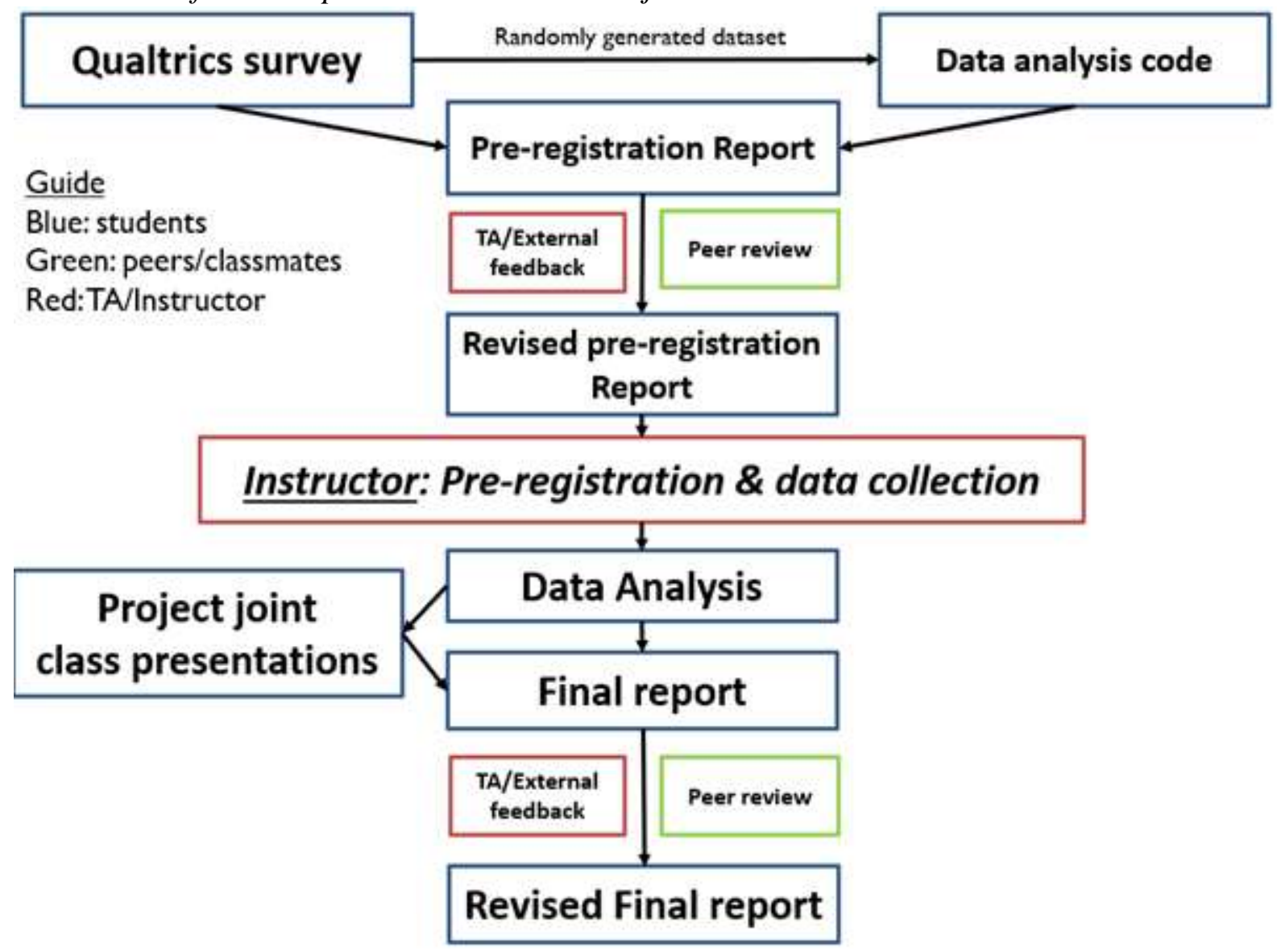

\section{Methods and items}

\section{Study 1}

Participants completed both the Self and Estimation (other) conditions for both the Paid and Unpaid conditions. Vignette introduction (both samples): "The blood supply in the United States has reached record lows in the past month. The American Red Cross will be coming to the community for a blood drive in several weeks. They have asked us to get some sense of how many residents will be willing to donate blood and what factors might make volunteering more attractive." 


\section{Table S1}

Study 1 IV and DV Text by Replication Sample (Differences Are Superficial)

\begin{tabular}{|c|c|c|}
\hline & IV: Paid Condition & IV: Unpaid Condition \\
\hline \multirow[t]{5}{*}{ MTurk } & $\begin{array}{l}\text { The Red Cross is now considering paying } \\
\$ 15 \text { to each individual who donates blood. }\end{array}$ & $\begin{array}{l}\text { The Red Cross is considering to collect } \\
\text { donations in the typical way without providing } \\
\text { any financial compensation. }\end{array}$ \\
\hline & \multicolumn{2}{|c|}{ DV: Willingness to Donate Blood } \\
\hline & $\begin{array}{l}\text { Would you donate blood if the Red Cross } \\
\text { were to pay } \$ 15 \text { ? (yes/no). }\end{array}$ & $\begin{array}{l}\text { Would you donate blood if the Red Cross you } \\
\text { were not to be paid? (yes/no). }\end{array}$ \\
\hline & \multicolumn{2}{|c|}{ DV: Estimating Others' Willingness to Donate Blood } \\
\hline & $\begin{array}{l}\text { We would like you to try to estimate as } \\
\text { accurately as you can what percentage of } \\
\text { your peers would donate blood if the Red } \\
\text { Cross were to pay } \$ 15 \text {. (Please answer in } \\
\text { number from } 0-100 \text { ) }\end{array}$ & $\begin{array}{l}\text { We would like you to try to estimate as } \\
\text { accurately as you can what percentage of your } \\
\text { peers would donate blood if they were not to be } \\
\text { paid. (Please answer in number from } 0-100 \text { ) }\end{array}$ \\
\hline Prolific & $\begin{array}{l}\text { Red Cross was considering paying } \$ 15 \text { to } \\
\text { each donor who donates blood. }\end{array}$ & $\begin{array}{l}\text { Red Cross were to collect donations in the } \\
\text { typical way, you would not receive any financial } \\
\text { compensation for their donations. }\end{array}$ \\
\hline \multicolumn{3}{|c|}{ DV: Willingness to Donate Blood } \\
\hline & $\begin{array}{l}\text { Would you donate blood if the Red Cross } \\
\text { were to pay } \$ 15 ?\end{array}$ & $\begin{array}{l}\text { Would you donate blood if you were not to be } \\
\text { paid? }\end{array}$ \\
\hline & \multicolumn{2}{|c|}{ DV: Estimating Others' Willingness to Donate Blood } \\
\hline & $\begin{array}{l}\text { Based on your estimation, what percentage } \\
\text { of your peers would donate blood for } \$ 15 \text { ? } \\
\text { (Please answer from } 0-100 \text { ) }\end{array}$ & $\begin{array}{l}\text { Based on your estimation, what percentage of } \\
\text { your peers would donate blood if they were not } \\
\text { to be paid? (Please answer from } 0-100 \text { ) }\end{array}$ \\
\hline
\end{tabular}

\section{Study 4}

Participants were randomized to either the Self or the Estimation (other) condition. Vignette introduction (both samples): "We are interested in how accurate people's estimates are of smokers' and nonsmokers' attitudes toward cigarette taxation and smoking restrictions. We are asking both smokers and nonsmokers to indicate whether they would support a number of proposals (e.g., "Would you support or oppose an increase in taxes on cigarettes?"). 


\section{Table S2}

Study 4 IV and DV Text (Differences Are Superficial Other Than the MTurk Extension)

\begin{tabular}{|c|c|c|}
\hline & IV: Self Condition & IV: Other (Estimation) Condition \\
\hline MTurk & $\begin{array}{l}D V: \text { Actual Support } \\
\text { Please indicate your support for the } \\
\text { smoking-related policies below. Do you } \\
\text { think there should be restrictions on } \\
\text { smoking in the following areas? }\end{array}$ & $\begin{array}{l}\text { DV: Estimated Support } \\
\text { We would like you to try to estimate as } \\
\text { accurately as you can the percentage of } \\
\text { smokers [nonsmokers] who indicate } \\
\text { support for each of the following proposals. }\end{array}$ \\
\hline Extension & 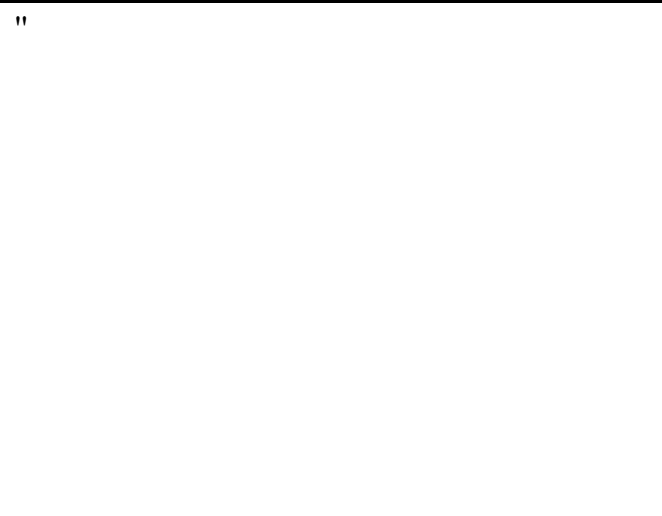 & $\begin{array}{l}\text { DV: Estimated Support } \\
\text { We would like you to try to estimate as } \\
\text { accurately as you can the percentage of } \\
\text { light smokers ( }<10 \text { cigarettes per day), } \\
\text { moderate smokers ( } 10-20 \text { cigarettes per } \\
\text { day), heavy smokers ( }>20 \text { cigarettes per } \\
\text { day), former smokers (not smoking } \\
\text { currently, but having smoked for more than } \\
6 \text { months) and nonsmokers (never smoked } \\
\text { for more than } 6 \text { months) who indicate } \\
\text { support for each of the following proposals. }\end{array}$ \\
\hline Prolific & $\begin{array}{l}\text { DV: Actual Support } \\
\text { Would you support an increase in taxes } \\
\text { on cigarettes, complete ban on cigarette } \\
\text { advertisement or complete ban on } \\
\text { cigarettes in public places? Do you think } \\
\text { there should be restrictions on smoking in } \\
\text { restaurants, workplaces, buses and trains, } \\
\text { airplanes, or hotels and motels? }\end{array}$ & $\begin{array}{l}D V \text { : Estimated Support } \\
\text { Based on your estimation, what's the } \\
\text { percentage for smokers who would support } \\
\text { the following policies? Based on your } \\
\text { estimation, what's the percentage for } \\
\text { nonsmokers who would support the } \\
\text { following policies? }\end{array}$ \\
\hline
\end{tabular}

\section{Communal Orientation Scale (Prolific Sample)}

Chen, Lee-Chai, \& Bargh (2001)

1. It bothers me when other people neglect my needs.

2. When making a decision, I take other people's needs and feelings into account.

3. I'm not especially sensitive to other people's feelings.*

4. I don't consider myself to be a particularly helpful person.*

5. I believe people should go out of their way to be helpful.

6. I don't especially enjoy giving others aid.*

7. I expect people I know to be responsive to my needs and feelings.

8. I often go out of my way to help another person.

9. I believe it's best not to get involved taking care of other people's personal needs.*

10. I'm not the sort of person who often comes to the aid of others.*

11. When I have a need, I turn to others I know for help. 
12. When people get emotionally upset, I tend to avoid them.*

13. People should keep their troubles to themselves.*

14. When I have a need that others ignore, I'm hurt.

Respondents rate each item on a seven-point scale from 1 (extremely uncharacteristic of me) to 7 (extremely characteristic of me). Items with an asterisk are reverse-coded.

\section{Table S3}

Paid vs. Unpaid Donation Willingness (Self) and Estimates (Others) in Study 1 Replications

\begin{tabular}{llrrrl}
\hline & Sample & $t$ & $d f$ & $d[95 \% \mathrm{CI}]$ & Interpretation \\
\hline \multirow{2}{*}{ Self } & MTurk & 8.50 & 798 & $0.29[0.22,0.35]$ & Signal Same Direction \\
& Prolific & 4.17 & 798 & $0.13[0.07,0.19]$ & Signal Same Direction \\
\multirow{2}{*}{ Others } & MTurk & 24.25 & 798 & $0.67[0.61,0.73]$ & Signal Same Direction \\
& Prolific & 23.66 & 798 & $0.64[0.58,0.70]$ & Signal Same Direction \\
\hline
\end{tabular}

Note. All $p$ s <.001. Paired-sample $t$-tests were conducted to contrast donation rates between Paid and Unpaid conditions. The interpretation is based on (LeBel et al., 2019), and the size of the effects could not be precisely compared to the original due to missing information. 


\section{Table S4}

Smokers vs. Nonsmokers Policy Support (Self Ratings) in Study 4 Replications Using PairedSamples t-Tests (MTurk N =799, Prolific $\mathrm{N}=799$ )

\begin{tabular}{llccc}
\hline Policy & Sample & $t$ & $p$ & $d[95 \% \mathrm{CI}]$ \\
\hline $\begin{array}{c}\text { Increase cigarette } \\
\text { taxation }\end{array}$ & MTurk & 7.40 & $<.001$ & $1.19[0.86,1.51]$ \\
& Prolific & 9.45 & $<.001$ & $1.42[1.15,1.68]$ \\
Ban cigarette ads & MTurk & 1.53 & .13 & $0.25[-0.06,0.55]$ \\
& Prolific & 4.26 & $<.001$ & $0.68[0.43,0.93]$ \\
Ban smoking in & MTurk & 6.82 & $<.001$ & $1.13[0.81,1.46]$ \\
public places & Prolific & 6.45 & $<.001$ & $0.93[0.68,1.18]$ \\
Restrict smoking in & MTurk & 3.12 & .003 & $0.60[0.29,0.91]$ \\
restaurants & Prolific & 3.10 & $<.003$ & $0.59[0.34,0.84]$ \\
Restrict smoking in & MTurk & 2.86 & .005 & $0.53[0.22,0.84]$ \\
workplaces & Prolific & 3.56 & $<.001$ & $0.65[0.40,0.90]$ \\
Restrict smoking on & MTurk & 1.54 & .13 & $0.28[-0.03,0.58]$ \\
buses and trains & Prolific & 2.63 & $<.01$ & $0.47[0.23,0.72]$ \\
Restrict smoking on & MTurk & 1.10 & .28 & $0.19[-0.11,0.50]$ \\
airplanes & Prolific & 2.62 & .01 & $0.52[0.28,0.77]$ \\
Restrict smoking in & MTurk & 4.32 & $<.001$ & $0.81[0.49,1.12]$ \\
hotels \& motels & Prolific & 5.05 & $<.001$ & $0.94[0.68,1.19]$ \\
Total $(M)$ & MTurk & 3.71 & $<.001$ & $0.43[0.21,0.65]$ \\
\hline & Prolific & 5.39 & $<.001$ & $0.55[0.37,0.73]$ \\
\hline
\end{tabular}




\section{Table S5}

Overestimation of Self-Interest by Policy in Study 4 (MTurk $\mathrm{df}=205$, Prolific $\mathrm{df}=398)$

\begin{tabular}{clccccl}
\hline Policy & Sample & $M$ & $S D$ & $t$ & $d[95 \%$ CI $]$ & Interpretation \\
\hline $\begin{array}{c}\text { Increase cigarette } \\
\text { taxation }\end{array}$ & MTurk & 43.4 & 30 & 20.5 & $1.43[1.23,1.62]$ & Signal Same Direction \\
& Prolific & 44.1 & 28 & 31.0 & $1.55[1.41,1.70]$ & Signal Same Direction \\
Ban cigarette ads & MTurk & 15.3 & 32 & 6.95 & $0.49[0.34,0.63]$ & Signal Same Direction \\
& Prolific & 12.9 & 31 & 8.41 & $0.42[0.32,0.52]$ & Signal Same Direction \\
Ban smoking in & MTurk & 36.0 & 32 & 16.1 & $1.12[0.95,1.30]$ & Signal Same Direction \\
public places & Prolific & 36.5 & 29 & 24.8 & $1.24[1.11,1.37]$ & Signal Same Direction \\
Restrict smoking in & MTurk & 22.0 & 33 & 9.45 & $0.66[0.51,0.81]$ & Signal Same Direction \\
restaurants & Prolific & 22.2 & 31 & 14.5 & $0.72[0.61,0.83]$ & Signal Same Direction \\
Restrict smoking in & MTurk & 20.7 & 31 & 9.72 & $0.68[0.53,0.83]$ & Signal Same Direction \\
workplaces & Prolific & 26.0 & 30 & 17.2 & $0.86[0.75,0.98]$ & Signal Same Direction \\
Restrict smoking on & MTurk & 16.5 & 33 & 7.22 & $0.50[0.36,0.65]$ & Signal Same Direction \\
buses and trains & Prolific & 20.7 & 31 & 13.5 & $0.68[0.57,0.79]$ & Signal Same Direction \\
Restrict smoking on & MTurk & 6.5 & 32 & 2.92 & $0.20[0.07,0.34]$ & Signal Same Direction \\
airplanes & Prolific & 13.0 & 33 & 7.87 & $0.39[0.29,0.50]$ & Signal Same Direction \\
Restrict smoking in & MTurk & 30.9 & 30 & 14.8 & $1.03[0.86,1.20]$ & Signal Same Direction \\
hotels \& motels & Prolific & 27.4 & 29 & 18.6 & $0.93[0.81,1.05]$ & Signal Same Direction \\
\hline
\end{tabular}

Note. One-sample $t$-tests. Interpretation was based on (LeBel et al., 2019), and effect sizes could not be precisely compared with the original because of missing variance. 